\title{
BIM for FM: A Case Support for Business Life Cycle
}

\author{
Ricardo Codinhoto $^{1}$ and Arto Kiviniemi ${ }^{2}$ \\ ${ }^{1}$ School of the Built Environment, The University Of Salford, The Crescent, Salford, \\ M5 4WT, United Kingdom \\ r.codinhoto@salford.ac.uk \\ ${ }^{2}$ School of Architecture, University of Liverpool, Liverpool, L69 3BX, United Kingdom \\ a.kiviniemi@liverpool.ac.uk
}

\begin{abstract}
Relatively little information exists about the use of BIM in the operation and maintenance of buildings. Reported cases of BIM adoption to support facilities management and lifecycle management reveals that the implementation of BIM for FM processes is, in general, limited to an experimental scale. Even large public owners who have been using BIM for managing their construction projects have not implemented it into their FM activities. Therefore, there is little evidence of the benefits of BIM in the operational phase. In addition, the challenges involved in shifting from traditional FM processes to new BIM-based processes are not well known. In this paper we document some of the issues involved in the adoption of BIM in FM and identify some applications, metrics and benefits related to its adoption. The findings are based on a case study carried out within a major re-development project in Manchester, UK. Results indicate a step rise in the level of awareness regarding potential benefits of BIM in FM activities and lifecycle information management.
\end{abstract}

Keywords: BIM, FM, Building Information Modelling, Facilities Management, Lifecycle Information Management.

\section{$1 \quad$ FM and Product and Service Life Cycle}

Modern Facilities Management (FM) conceptualisation recognises the importance of FM within the business life cycle. Traditionally, the FM function was widely described as involving clients, real estate and AEC teams, all planned around a cost factor to be spent on non-value adding activities such as the maintenance and cleaning of a building, and the provision of support services such as reprographics, reception, stationery [1], [2]. This view has changed considerably. For example, for the British Standards Institute (BSi) FM refers to "the integration of processes within an organisation to maintain and develop the agreed services that support and improve the effectiveness of its primary activities" [3]. The Institute of Asset Management (IAM) PAS 55-1:2008 also emphasises the importance of FM to the life cycle of products and services.

The effectiveness of many organisations is certainly dependent on the way its facilities are managed. Effectiveness can be measured in different ways that maintain 
strong links with the mission, goals and objectives of the organisation, the influence of its stakeholders [4] and the profit in its operations. To succeed, businesses must recognise that the rising cost of occupying buildings, providing services to support operations and improving working conditions are fundamental factors impacting the business life cycle. As such, business pressures to improve quality, reduce cost and minimize risks continue to drive FM decisions [4]. If profitability is to be achieved, business owners must make strategic choices related to managing facilities.

It is argued that effectively planned facilities and supporting services can create significant business returns [4]. This can be seen through introducing professional FM methods to support increased efficiency [5], [6], on-going responsibility for the continuous operation of services [7] and a holistic view of the dynamics of the workplace amongst the product design and production of the physical workspace, and also between people and processes, and people and their environment [4].

Despite evidence existing to demonstrate the link between FM and an organisation's success, in practice FM is often seen as a 'fire fighter' service. It is not uncommon to see facilities managers taking a reactive approach in their activities, waiting for instructions before any action is taken. As a result, constantly emerging issues have to be remediated quickly without planned assessment of the best long-term solution [8]. This approach, in general, leads to poor service delivery, dissatisfied customers and loss of value to the organisation that does not operate efficiently. Generally, poor FM delivery is seen in organisations where the business strategy is not effectively aligned with building/asset/service management [9].

In this respect, the sought alignment between business and FM has been continuously evolving as a reflection of, amongst other things, the effectiveness of the information technology and communication systems within organisations [10], [7]. Effective information management forms a critical aspect in the ability of FM teams to coordinate processes so as to achieve the required output, [4] whilst providing valuable information to planners, designers and corporate decision makers [7].

However, the efficient utilisation of information, its management and its supporting technology in FM has been somewhat problematic [8], [10], [11]. Facilities managers can have access to a variety of data sources but the opportunities to utilise or manipulate data are frequently unexploited [8]. Often, systems designed to generate the necessary information required by senior executives to make decisions are lacking [4] with current solutions relying on the duplication of data leading to the overprocessing of this data and information overload [8].

A way of resolving this challenge is to invest in appropriate information management resources. This investment should aim at making information processing easier [8] and it is important that facilities managers evaluate alternative simple and appropriate systems to ensure that they meet the organisation's needs [12]. By easing information overload, the FM team has a greater chance of knowing exactly what is expected of them, thus procedures such as work programmes, service level agreements, maintenance schedules, meeting schedules can be instituted [8].

In this respect, the use of building information modelling (BIM) has been investigated as a way to support the reduction of unnecessary processes through better integration of information in FM [13], [14]. However, whilst its use within the design and 
construction phase is well studied [14], its adoption for FM purposes is still embryonic, in general, due to a lack of skills in the sector [15].

An often-introduced claim is that BIM can be a powerful tool for facility managers to improve buildings' performance and manage operations more efficiently throughout their life cycle. Although this claim has been common since the early introduction of BIM, there is relatively little information about the real use of BIM in the operation and maintenance of buildings. Even most large public owners who have been early adopters of BIM, such as GSA, USACE or Senate Properties, have used BIM more in managing their construction projects than into their FM activities.

Indeed, the literature shows that very little has been implemented extensively in FM and even less has been measured in terms of improvements made due to BIM. In the following, twenty BIM FM related articles reporting on case studies were analysed to identify BIM capabilities implemented in case studies and also to identify the measures of success used that can be related to Return on Investment. As shown in Table 1, the application of BIM to FM has been focused on Hard FM to a great extent and in particular on the accuracy of 3D as-built models and the link to digital statutory/maintenance/supplier information available through online services.

Table 1. FM related BIM capabilities explored and implemented in the literature

\begin{tabular}{|c|c|c|c|c|c|c|c|c|c|c|c|c|c|c|c|c|c|c|}
\hline Capabilities / Cases & $\underline{\theta}$ & $\Xi$ & $\stackrel{\infty}{\exists}$ & $\Xi \Xi$ & $\vec{v} \overline{\mathrm{v}}$ & ב & ב & I & & ¿े: & 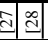 & בे & & $\bar{m}$ & & $\hat{m}$ & & 6 \\
\hline Elimination of duplicated and inaccurate data through 3D modelling & - & & & & & & & & & & & $\bullet$ & & & & & & \\
\hline Analyse and simulate design to support preventive and reactive maintenance & - & $\bullet$ & & & & $\bullet$ & & & - & & & & & & & & & \\
\hline Life cycle costs and environmental analysis & - & & & & & & & & & & & & & & • & • & & \\
\hline 4D as-built model containing construction process information & & & • & & & & & & & & & & & & & & & \\
\hline 3D as-built model & & & $\bullet$ & $\bullet \cdot \bullet$ & & $\cdot$ & $\bullet$ & & & & & $\bullet$ & & & $\bullet$ & & $\bullet$ & \\
\hline 3D as-built model linked to estatutory/maintenance information & & & & & $\bullet$ & & & & & & & $\bullet$ & $\bullet$ & & $\bullet$ & $\bullet$ & & \\
\hline 3D linked to cleaning schedule & & & & & & $\bullet$ & & & & & & & & & & & & \\
\hline 3D linked to waste disposal schedule & & & & & & $\cdot$ & & & & & & & & & & & & \\
\hline Maintenance linked to expenditure history & & & & & & • & & & & & & & & & & & & \\
\hline Order/supply linked to inventory schedule & & & & & & $\bullet$ & & & & & & $\bullet$ & $\bullet$ & & • & $\bullet$ & - & \\
\hline Energy Simulation witin as-built & & & & & & & $\bullet$ & & & & & . & . & & & & & \\
\hline Maintenance schedule & & & & & & & & $\cdot \dot{-}$ & - & & & $\cdot$ & $\bullet$ & $\bullet$ & & & & \\
\hline Accurate as-built model & & & & & & & & & & - & & & & & & . & $\bullet$ & \\
\hline Maintenance as-done record of event/problem description and solution & & & & & & & & & & & $\cdot \cdot \cdot$ & & & & & $\cdot$ & $\bullet$ & \\
\hline Real-time, mobile resource location tracking & & & & & & & & & & & $\cdot$ & & & & & & & \\
\hline Facility condition analysis & & & & & & & & & & & & & & $\bullet$ & & & & \\
\hline Building Automation System & & & & & & & & & & & & & & & $\bullet$ & & & \\
\hline Travelling path of maintenance & & & & & & & & & & & & & & & & & & - \\
\hline
\end{tabular}

In regards to measures of success, 'a facility manager is responsible for making critical strategic, tactical, and operational facilities-planning decisions that affect the organization's business performance' [17]. In this respect, a taxonomy of indicators of success in the implementation of BIM for FM purposes composed of a) financial indicators related to costs and expenditures associated with operation and maintenance, energy, building functions, real estate, plant, etc.; b) Physical indicators associated with the physical shape and conditions of the facility, buildings, systems, and components; c) functional indicators related to the way the facility and the buildings function and which express building appropriateness through space adequacy, parking, etc.; and d) survey-based indicators, which are based solely on respondents' 
opinion to surveys that are primarily qualitative in nature [37]. In this respect, Table 2 shows metrics used to identify benefits from adopting BIM for FM purposes across many case studies. To a large extent, most of the results obtained in the studies are based of the testimony of managers rather than from a systematic collection of information.

Thus, despite progress being made in terms of advancing the knowledge regarding the adoption of BIM for FM, very little hard evidence is reported in the literature regarding how effective or ineffective BIM based FM processes are in relation to solving FM problems so to justify BIM implementation. Despite the existence of positive testimony that BIM improves FM, a lack of diagnostics for FM problems and baseline measures, BIM in FM is still a solution looking for a problem.

Table 2. Metrics used to identify benefits from adopting BIM for FM

\begin{tabular}{|c|c|c|c|c|c|c|c|c|c|c|c|c|c|c|c|c|c|c|c|c|}
\hline Baseline Measure & $\underline{-6}$ & $\Xi$ & & $\bar{\Xi}$ & a) & & ปิ & ב & $\stackrel{\Xi}{ \pm}$ & $\sqrt[3]{3}$ & ปు & 고 & & & & & $\bar{\varrho}$ & & & 궁 \\
\hline Better customer service & $\bullet$ & & & & & & & & & & & & & & & & & & & \\
\hline Better decision-making & $\bullet$ & $\bullet$ & & & & & & - & & $\bullet$ & $\bullet$ & & & & & $\bullet$ & $\bullet$ & & & $\bullet$ \\
\hline Better cost forescast & & - & & & & & - & & & & & & & $\bullet$ & & . & & & & \\
\hline Improved data consistency & & & - & & - & & - & - & & & & $\cdot$ & & & - & - & & $\cdot$ & $\cdot$ & \\
\hline Better access to information & & & & $\cdot$ & & & & & & & & $\cdot$ & & & & & & $\cdot$ & $\cdot$ & \\
\hline Reduced response time & & & & & - & & & & & & & & & & & & & & & \\
\hline Increased process efficiency & & & & & & $\cdot$ & & & & & & & & - & & & & & & 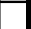 \\
\hline Better planning & & & & & & & $\bullet$ & & & & & & & $\bullet$ & $\cdot \bullet$ & & & & & \\
\hline Better AEC-FM Integration & & & & & & & & & $\cdot$ & & & & & & & & & & & \\
\hline Reduction of maintenance failure & & & & & & & & & & & - & & & & & . & & & . & . \\
\hline Strealined processes & & & & & & & & & & & - & & . & & . & - & & $\bullet$ & - & $\bullet$ \\
\hline Improved tracking of inventory & & & & & & & & & & & & & - & - & - $\bullet$ & & & & & \\
\hline Reduction of reactive maintenance & & & & & & & & & & & & & & - & & & & & & 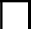 \\
\hline Reduced cost of operations & & & & & & & & & & & & & & $\bullet$ & - $\bullet$ & & & & & . \\
\hline Reduced time of operations & & & & & & & & & & & & & & & - & & $\bullet$ & & & \\
\hline Reduce effort of operations & & & & & & & & & & & & & & & & & & & & $\cdot$ \\
\hline
\end{tabular}

\section{Case Manchester Town Hall Complex}

This research was done in the context of the UK Government's BIM initiative. Further understanding of the key issues in migrating to BIM-FM is crucial to the development of general guidance. The research strategy was Case Study Research, carried out to investigate the use of BIM FM in the Manchester City Council Town Hall Complex (MCC THC) project and followed a previous investigation during the design and construction phase of the same project in 2011 [29], [39]. The tools and methods used for data collection included a literature review on FM and ICT related topics, and interviews with project team members and FM team members. It also involved the use of the NBIMS Capability Maturity Matrix [38], archival analysis of documentation and a workshop for data validation. The sources of evidence utilised included information extracted from the BIM alongside verbal and written explanations describing integrated processes as provided by six members of the FM team. 
THC FM Structure: The FM services are organised in a distinctive way. At the macro level, services are divided between front and back-office activities. Within back-office services there are two categories, namely FM Support and Building Support. FM support refers to secondary activities that are directly linked to the provision of primary services. Building support, on the other hand is related to the overall maintenance of the fabric. In this category, there are three levels of 'maintenance': planned preventive maintenance, reactive maintenance and capital projects (i.e. major redevelopments of the facility). In relation to front-office services, there are two categories: housekeeping and customer support. Housekeeping, in general, refers to activities that are performed regularly such as cleaning and waste collection, whilst customer support refers to activities dealing directly with visitors and suppliers to the THC. A BIM was developed to aid building support activities in the main. ICT (hardware, software and systems management) is not managed in coordination with FM. According to the FM interviewees, this disconnection between FM and ICT is an extremely relevant barrier to the adoption of BIM for FM.

With regards to BIM, its depiction for the FM team consists of four systems: CPAD, ArtrA, eDocuments and UE. C-PAD is the current system used for logging issues raised by end users and non-compliant technical audits. ArtrA, the software which serves as a user friendly interface to access 3D building information on BIM and a cloud-based repository of information (eDocuments), supports this process by making available electronic versions of documents such as statutory requirements and building data, maintenance reports, etc. In this respect, data structure (including building geometry) within ArtrA is hyperlinked to relevant documentation in eDocuments and vice-versa. The maintenance service provider uses the UE as their accounting system and discussions have started regarding the possibilities of increasing UE interoperability.

FM Problems: When the FM team was prompted to identify the benefits of BIM adoption during the initial stages of the research, quite often the answers were related to design and construction benefits such as automated clash detection, support for decision-making, automated costing. Even though these benefits were important for the project, their direct relationship with business core activities or FM was limited or nonexistent. As BIM awareness increased within the FM team the focus shifted to the identification of opportunities for FM service improvement (Table 3).

Table 3. FM problems potentially benefiting from BIM FM implementation

\begin{tabular}{l}
\hline Problems \\
\hline \hline Data entry procedure was repeated in triplicate for reactive maintenance \\
\hline Errors due to manual input of information within different system \\
\hline Incompletion of planned maintenance due to delays in reactive maintenance \\
\hline Time spent on finding correct information to support building maintenance \\
\hline Lack of information regarding FM performance \\
\hline Lack on links between back and front offices services \\
\hline Errors in the statutory maintenance record due to symmetrical characteristic of the facility
\end{tabular}


BIM FM Maturity: The results presented here (Table 4) highlight the perspective of the FM team within MCC THC on the level of maturity of BIM as applied to the reactive maintenance process. Overall, these results show that high levels of maturity have been attributed to the areas directly related to graphical information development, whilst lower scores have been attributed to areas related to business functions. As argued by the FM team, business functions are not yet linked with FM results. The process for assessment used also revealed that the FM team still face a degree of uncertainty related to their understanding of the actual level of BIM maturity.

Data richness: interviewees agreed that BIM was established, but with only very basic data loaded. Their perception is that additional data has gradually been made available and that data is beginning to be accepted as an authoritative primary source.

Life-cycle view: data was gathered as it was made available throughout the project, however no single phase (design, construction and use) was totally authoritative or complete. One participant indicated that a fourth phase of the facilities lifecycle has been added and some information is flowing.

Table 4. Cumulative assessment of maturity from the FM team (reactive maintenance)

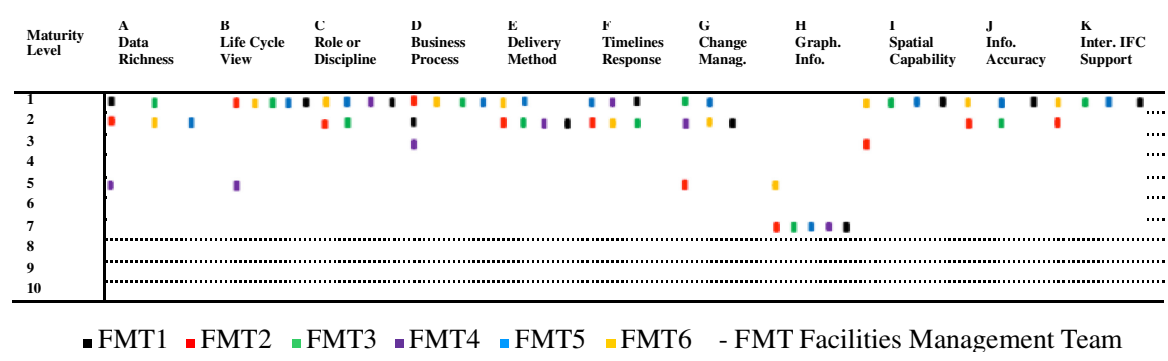

Roles or discipline: Roles apply to people's jobs at this level but no roles are fully supported through BIM. Contradicting this conclusion, two members of the FM team believe that the Service Resident Engineer uses BIM for entering data and via building geometry can access related documentation; for them his role is fully supported through BIM.

Business process: Business processes are not completely defined and therefore cannot be used to store information in the BIM. However, to a limited extent, crossdepartmental integration has begun, as a few business processes are being designed to collect information to maintain the BIM in the organization.

Delivery method: Despite the BIM being accessible, it is not on a network and there is control over who can access it. This is to be kept this way until the FM team develops enough confidence to operate the BIM.

Timelines / response: The information is stored and managed only on the "room data sheet" through an external database in ArtrA Software. Currently, the system is not designed to reply to a set of pre-determined enquires. The model is under development and as such it is not completed or automated. However, reports can be generated from the service order request logs in C-Pad, and building geometry (in ArtrA) is 
linked to building documentation (in eDocuments), thus indicating some level of timeliness / response.

Change management: Awareness exists that there is change management process for BIM in place at project level, however there is lack of clarity regarding to whether this will be extended to the organisation.

Graphical information: Drawings are 3D object based and have intelligence. The MCC FM team has achieved this by using the software solution ArtrA (Figure 1). Within ArtrA, each asset, such as the MEP asset, has a location based asset identifier and a unique webpage reference generated by eDocuments. Currently, information provided via eDocuments is in non-intelligent PDF format. Visualisation of the model is possible in different packages; however, loss of intelligent information happens if functional model manipulation is needed.

Spatial capability: The facility is recognized in a worldview spatially and the common coordinate system was inherited from the architectural model. Despite the space not being spatially located in the real world according to a GPS/GIS system (as indicated in the CMM) the current system adopted constitutes a BIM capability.

Information accuracy: To date, electronic validation of information for internal spaces is available to a limited extent. This is due to limited interoperability, where in some instances data from information structure in one model is lost during exchange, thus leading to gaps and duplication in the information model where data has to be reentered manually (Figure 1).

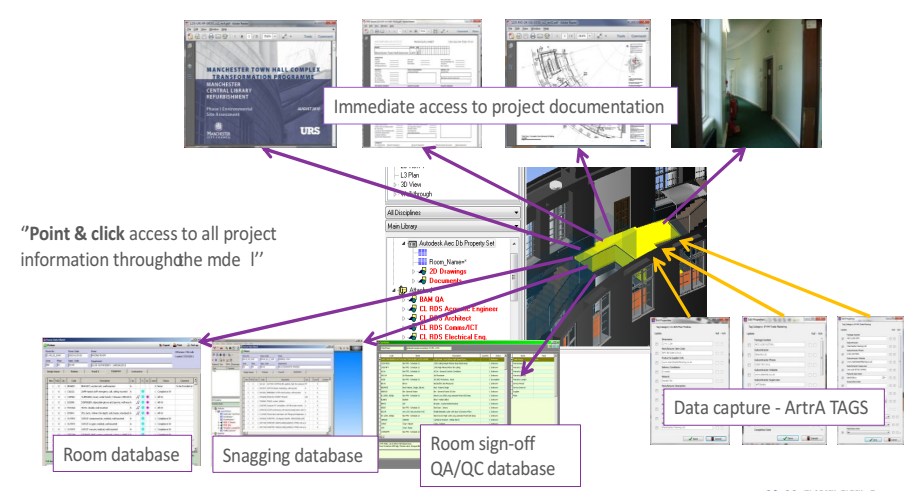

Fig. 1. ArtrA graphical information displays rich contextual information in a 3D model

Interoperability / Exchange support: some interoperability exists that is not yet automatic or seamless. Interoperability was achieved by using COBie for exchanging information from ArtrA (portable 3D intelligent data set), C-Pad (management) and eDocuments (archival register). These applications form a system linked via relationships that enables automatic updating of data and information. Data and information entry can be done from existing models, manually from archival documentation or survey. Key stakeholders within the facilities management team are tasked to author and review the information. 
Overview: As expected, the overall results achieved by MCC Reactive Maintenance Services are low if analysed independently. That does not mean that MCC is not performing well in the implementation of BIM. Comparatively with the industry in general, the efforts put forward in the implementation are quite remarkable, considering that technology is not ready for full adoption, thus imposing a constraint in higher scores.

Barriers: the research identified many barriers that hindered the implementation of BIM in the THC project. Examples of the identified barriers include the necessary technical expertise to generate and operate BIM, readiness for a fast implementation, the completion of the model before completion of construction to assist hand-over activities, lack of organisational buy in and most importantly the separation of MCC ICT from FM. Table 5 shows the barriers to implementation identified during the research.

Benefits and Returns from BIM FM: several benefits were identified for all phases of the project (i.e. design, construction and use). With regards to the benefits for the design and construction phase, these were related to support to decision-making and the reduction of errors and risks on site. A series of simulations revealed that many potential gains in terms of time, human resources and finance can be achieved (Table 6). Above all, faster maintenance process will lead to shorter service disruption, thus enhancing the support to business core activities and customer satisfaction.

Table 5. Barriers to the implementation of BIM FM within the THC

\begin{tabular}{l}
\hline Barriers \\
\hline \hline Technical expertise needed for the maintenance and updating of the BIM \\
\hline Number of process changes made simultaneously \\
\hline Risk of underperform whilst changing from current to BIM enabled process \\
\hline Limited software interoperability \\
\hline Lack of guidance, protocols and standards for BIM FM \\
\hline Unclear BIM FM requirements at early project stages \\
\hline Model incompletion at project hand over stage \\
\hline Lack of clarity regarding model assembly and its relationship with FM processes \\
\hline lack of cross functional buy in wihtin the organisation
\end{tabular}

Table 6. Benefits and returns from BIM FM (Adapted from MCC, 2013)

\begin{tabular}{|l|l|l|c|c|c|c|c|c|}
\hline \multirow{2}{*}{\multicolumn{1}{c|}{ Scenario }} & \multicolumn{2}{c|}{ Traditional } & \multicolumn{2}{c|}{ BIM Enabled } & \multicolumn{3}{c|}{ Savings } \\
\cline { 2 - 9 } & Time & Man/hours & Time & Man/hours & Time & Man/hours & $£$ \\
\hline Ventilation motor replacement & 4 weeks & 14 & 1 day & 3 & 27 days & 11 & $£ 286.00$ \\
\hline Alcove light replacement & 6 weeks & 10 & 1 day & 2 & 40 days & 8 & $£ 108.00$ \\
\hline Extract duct - unknown water build up & 12 weeks & 23 & 1 day & 10 & 92 days & 13 & $£ 838.00$ \\
\hline Public lift repair & 5 weeks & 16 & 2 days & 6 & 32 days & 10 & $£ 260.00$ \\
\hline Ceiling leak in heritage area & 3 days & 14 & 1 day & 3 & 2 days & 11 & $£ 286.00$ \\
\hline
\end{tabular}




\section{Discussion and Conclusions}

A great deal of effort has been made in the UK towards the adoption of BIM within the construction sector. However, once construction is finished, the use of the large and rich amount of information generated within project phases has not been explored to the same extent. The literature in this area shows that, despite many attempts to BIM FM implementation exists, these are still piecemeal and FM cases showing extensive use of BIM are lacking. The identified challenge faced by facilities managers relates to the lack of integration and transparency across organisational functions. Integration seems to be discussed as the way forward for the sector and BIM has been considered as a facilitator of this process. However, the lack of evidence demonstrating its benefits generates scepticism within managers. Also, the lack of FM "terminology" and understanding about how it applies to FM (being most of the discussions around design and construction) also contributes to the promotion of misunderstood perspectives of how BIM supports FM, whilst paradoxically also generating inflated expectations. As identified through this research, the ownership of the implementation process is not yet in the hands of FM teams. Much effort is still made by design and construction teams to provide information modelling services to assist FM teams. In this regard, the clarification that roles and responsibilities do not automatically change with BIM implementation is crucial. However, an adequate system must be in place to support authoring of information at all instances. The maintenance of a performance baseline and a history of critical services that can support the prioritization of services are also fundamental.

Conversely to the FM sector in general, the initial findings indicate that MCC despite being at early stages of BIM implementation has progressed rapidly, positively pushing the boundaries of BIM adoption for FM purposes. It is clear from the research that the willingness of MCC to implement BIM and their vision in using BIM to improve FM has been paramount to this fast development. One of the most relevant changes is in the attitude of the FM team that became more process oriented and is seeking to identify process inefficiencies that could be mitigated by the adoption of BIM. In other words, the MCC FM team is not just following a trend, rather the team is focused on promoting continuous improvement by setting new standards for the management of facilities making use of BIM whenever appropriate. This approach is creating an MCC construction knowledge asset base - information assets that improve the future management of this and other projects. With the support of this research, the FM team became aware of their advanced position in relation to traditional FM practices as well as of the path for redefining the process model for FM in public building projects and further BIM implementation and development.

Acknowledgments. Our special thanks to the BIS for funding this research, and to Mark Bew (Chairman of the UK Government BIM Implementation Group) and Liam Brady (Town Hall Complex Client Programme Manager) for their support to the research collaboration between the University of Salford and Manchester City Council. 


\section{References}

1. Thomson, T.: The essence of facilities management. Facilities 8(8), 8-12 (1990)

2. Tay, L., Ooi, J.T.L.: Facilities management: a 'Jack of all trades'? Facilities 19(10), 357-363 (2001)

3. British Standards Institute: Facility Management - Part 1: Terms and definitions: BS EN 15221-1:2006, vol. 44, 19p. BSI Standards Publication, London (2007)

4. Alexander, K.: Facilities Management: Theory and Practice. E \& F N Spon, London (1996)

5. Amaratunga, D., Haigh, R., Sarshar, M., Baldry, D.: Assessment of facilities management process capability: A NHS facilities case study. International Journal of Health Care Quality Assurance 15(6), 277-288 (2002)

6. Lennerts, K., Abel, J., Pfründer, U., Sharma, V.: Reducing health care costs through optimised facility management-related processes. Journal of Facilities Management 2(2), 192-206 (2003)

7. Atkin, B., Brooks, A.: Total Facilities Management, Facilities, 3rd edn., vol. 12. WileyBlackwell, Oxford (2009)

8. Barrett, P.S., Baldry, D.: Facilities Management: Towards Best Practice, 2nd edn. Facilities Management, vol. 2. Wiley-Blackwell, Oxford (2003)

9. Amaratunga, D., Baldry, D.: A conceptual framework to measure facilities management performance. Property Management 21(2), 171-189 (2003)

10. Abel, J., Diez, K., Lennerts, K.: A Standard Database Model for Computer Aided Facility Management in Hospitals. In: Proceedings of the Joint International Conference on Computing and Decision Making in Civil and Building Engineering, Montréal, Canada, pp. 535-542 (2006)

11. Bainbridge, M., Finch, E.F.: Getting the attention the facilities manager deserves. Facilities 27(7/8), 277-290 (2009)

12. BIFM: The Good Practice Guide to Selecting FM Software, The Good Practice Guide, Hertfordshire, 22p. (2006)

13. Ballesty, S., Mitchell, J., Drogemuller, R., Schevers, H., Linning, C., Singh, G., Marchant, D.: Adopting BIM for facilities management: Solutions for managing the Sydney Opera House. Cooperative Research Centre for Construction Innovation. Report, pp. 1-32 (2007)

14. Eastman, C., Teicholz, P., Sacks, R., Liston, K.: BIM Handbook: A Guide to Building Information Modeling for Owners, Managers, Designers, Engineers, and Contractors. John Wiley \& Sons, Inc., New Jersey (2008)

15. Cracknell, D.: Sector BIM Strategy: Improving BIM Education \& Training, The Higher Education Academy,

http: / /www. heacademy.ac.uk/assets/documents/disciplines / built_environment/BIM/BIM_Skills_CIC_David_Cracknell.pdf (accessed March 2014)

16. Innovation, CRC Construction: Adopting BIM for facilities management: Solutions for managing the Sydney Opera House. Cooperative Research Center for Construction Innovation, Brisbane, Australia (2007)

17. Lavy, S., Shohet, I.M.: Computer-Aided Healthcare Facility Management. Journal of Computing in Civil Engineering 21(5), 363-372 (2007)

18. Goedert, J., Meadati, P.: Integrating Construction Process Documentation into Building Information Modeling. Journal of Construction Engineering and Management 134(7), 509-516 (2008) 
19. Khanzode, A., Fischer, M., Reed, D.: Benefits and lessons learned of implementing building virtual design and construction (VDC) technologies for coordination of mechanical, electrical, and plumbing (MEP) systems on a large healthcare project, 324-342 (2008)

20. Akcamete, A., Alkinci, B., Garrett Jr., J.H.: Motivation for Computational support for Updating Building Information Models (BIMs). In: Workshop on Computing in Civil Engineering, pp. 523-532 (2009)

21. Fruchter, R., Schrotenboer, T., Luth, G.P.: From Building Information Modeling to Building Knowledge Model. In: Proceedings of the 2009 ASCE International Workshop on Computing in Civil Engineering, Austin, TX, June 24- 27, pp. 380-389 (2009)

22. Onyenobi, T.C., Arayici, Y., Egbu, C.O., Sharman, H.K.: Project and facilities management using BIM: University of Salford relocation management to Media City (2010)

23. Woo, J., Wilsman, J., Kang, D.: Use of As-Built Building Information Modeling, Construction Research Congress, 538-548 (2010)

24. Ospina-Alvarado, A.M., Castro-Lacouture, D.: Interaction of Processes and Phases in Project Scheduling Using BIM for A/E/C/FM Integration, Construction Research Congress 2010: Innovation for Reshaping Construction Practices, pp. 939-948 (2010)

25. Hao, Q., Xue, Y., Shen, W., Jones, B., Zhu, J.: A Decision Support System for Integrating Corrective Maintenance, Preventative Maintenance and Condition-based Maintenance. In: Construction Research Congress, pp. 470-479 (2010)

26. Tang, P., Huber, D., Akinci, B., Lipman, R., Lytle, A.: Automatic reconstruction of asbuilt building information models from laser-scanned point clouds: A review of related techniques. Automation in Construction 19, 829-843 (2010)

27. Su, Y.C., Lee, Y.C., Lin, Y.C.: Enhancing Maintenance Management Using Building Information Modeling in Facilities Management. In: Proceedings of the 28th International Symposium on Automation and Robotics in Construction (2011)

28. Costin, A., Pradhananga, N., Teizer, J.: Integration of passive RFID location tracking in Building Information Models (BIM). In: EG-ICE, Int. Workshop, Herrsching, Germany, pp. 4-6 (2012)

29. Codinhoto, R., Kiviniemi, A., Kemmer, S., Da Rocha, C.G.: BIM Implementation: Manchester Town Hall Complex. SCRI Report Series 6 (2011),

http://live.scri.salford.ac.uk/wpcontent/uploads/2011/12/MCC_Final_Research_Report.pdf

30. Aladham, O., Gonzales, J., Grant, I., Harper, K., Kruger, A., Nannis, S., Patel, A., Snedeker, L.: Case Study 1: MathWorks. In: Teicholz, P. (ed.) BIM for Facility Managers. Wiley (2013)

31. Beatty, R., Kim, K.: Case Study 2: Texas A\&M Health Science Center - A case study of BIM and COBie for Facility Management. In: Teicholz, P. (ed.) BIM for Facility Managers. Wiley (2013)

32. Aspurez, V., Lewis, A.: Case Study 3: USC School of Cinematic Arts. In: Teicholz, P. (ed.) BIM for Facility Managers. Wiley (2013)

33. Afedizie, E., Beatty, R., Hanselman, E., Heyward, E., Lawal, A., Nimer, E., Rosenthal, L., Siman, D.: Case Study 4: Implementation of BIM and FM at Xavier University. In: Teicholz, P. (ed.) BIM for Facility Managers. Wiley (2013)

34. Lewis, A.: Case Study 5: State of Wisconsin Bureau of FM, Division of State Facilities, Department of Administration. In: Teicholz, P. (ed.) BIM for Facility Managers. Wiley (2013)

35. Lewis, A.: Case Study 6: University of Chicago Administration Building Renovation. In: Teicholz, P. (ed.) BIM for Facility Managers. Wiley (2013) 
36. Wang, Y., Wang, X., Wang, J., Yung, P., Jun, G.: Engagement of facilities management in design stage through BIM: framework and a case study. Advances in Civil Engineering (2013)

37. Lavy, S., Garcia, J.A., Dixit, M.K.: Establishment of KPIs for facility performance measurement: review of literature. Facilities 28(9/10), 440-464 (2010)

38. National Institute of Building Sciences. US National Building Information Modelling Standard, Version 1 - Part 1: Overview, Principles and Methodologies (2007), http : / / www . wbdg.org / pdfs / NBIMSv1_p1.pdf (last accessed November 2009)

39. Kiviniemi, A., Codinhoto, R.: Challenges in the Implementation of BIM for FM: Case Manchester Town Hall Complex. In: Proceedings: ICCCBE and CIB W078 2014, Disney World, Orlando, Florida, USA, June 23-25 (2014) 